\title{
The Causal Effect of Stop-Loss and Take-Gain Orders on the Disposition Effect
}

\author{
Urs Fischbacher \\ University of Konstanz, Thurgau Institute of Economics
}

Gerson Hoffmann

Thurgau Institute of Economics

\section{Simeon Schudy}

LMU Munich

\begin{abstract}
We investigate whether automatic selling devices causally reduce investors' disposition effect (DE) in a laboratory experiment. Investors can actively buy and sell assets. Investors in the treatment group use stop-loss and take-gain options to automatically sell assets. In addition, we introduce a reminder condition that reminds investors about their selling plan if a limit is hit. Results show that the automatic selling device treatment significantly reduces the DEs, but the reminder treatment does not. Thus, the opportunity to ex ante commit to automatically selling at a loss causally reduces the disposition effect. (JEL C91, G02, G11)
\end{abstract}

The tendency to sell winning stocks more frequently than losing stocks, known as the disposition effect, is one of the most frequently observed and discussed biases of financial investors. Since the seminal work by Shefrin and Statman (1985), the disposition effect has been studied in a vast number of theoretical and empirical investigations. A series of empirical studies proved its existence in different trading environments and a variety of theories have been proposed to explain the disposition effect. However, the underlying causes of the disposition effect still remain unclear. ${ }^{1}$

We thank Lisa Bruttel, Katharine Bendrick, Fadong Chen, Gerald Eisenkopf, Konstantin Hesler, Konstantin Lucks, Johannes Maier, Stefan Nagel, Tibor Neugebauer, Stefan Palan, Katrin Schmelz, Doron Sensino, Thomas Stöckl, Stefan Trautmann, and Irenaeus Wolff, as well as participants of the Brown Bag Lunch Seminar at University of Innsbruck, the Experimental Finance Conference 2013 at Tilburg, the EEA-ESEM 2013 in Gothenburg, the International Meeting of Experimental and Behavioral Economics (IMEBE) 2013 in Madrid, and the ESA Meeting 2012 at New York University for helpful thoughts and comments. Supplementary data can be found on The Review of Financial Studies web site. Send correspondence to Urs Fischbacher, University of Konstanz, Universitätsstrasse 10, 78457 Konstanz, Germany; telephone: +49 7531882652. E-mail: urs.fischbacher@uni-konstanz.de.

1 See, for example, Odean (1998), who uses data from a U.S. broker to identify the "disposition effect" in the field and Weber and Camerer (1998), who first identified the disposition effect in a laboratory experiment, 
On the one hand, prospect theory may-under certain assumptions-explain the disposition effect (for discussion, see, e.g., Barberis and Xiong 2009; Hens and Vlcek 2011; Kaustia 2010b; Henderson 2012; Li and Yang 2013). On the other hand, pride seeking and regret minimization (see Muermann and Volkman 2006; Bleichrodt, Cillo, and Diecidue 2010; O'Curry Fogel and Berry 2006), models of realization utility (see, e.g., Shefrin and Statman 1985; Barberis and Xiong 2009, 2012; Frydman et al. 2014), as well as self-control problems (in combination with prospect theory or realization utility), may explain the existence of the disposition effect. For instance, Barberis $(2012,50)$ suggests that "a naive investor [...] may exhibit a "disposition effect" in his trading even though he planned to exhibit the opposite of the disposition effect." The current study uses an experimental approach that provides novel insights on the underlying reasons for the disposition effect and highlights the important role of time-inconsistent behavior for the disposition effect. Further, our results shed new light on the recent discussion about whether the disposition effect is driven by preferences or beliefs (see, e.g., Ben-David and Hirshleifer 2012), as well as on the idea that the disposition effect is caused by cognitive dissonance (Chang, Solomon, and Westerfield 2016).

We study the causal effects of (1) automatic selling devices and (2) prespecified selling plans with reminders but without automatic trade realizations on investors' disposition effects. Doing so allows us not only to identify which of these measures can causally reduce the disposition effect but, more importantly, to draw conclusions for the theoretical reasons behind the disposition effect. Our experiment builds on the work of Weber and Camerer (1998), who have shown that forced sales of all stocks at the beginning of every trading period significantly reduce the disposition effect. ${ }^{2}$ In contrast to Weber and Camerer (1998), we focus on an environment in which investors have the opportunity to decide themselves if and at what price limit their assets are automatically sold. This novel design feature allows us to highlight the important role of time-inconsistent behavior for the disposition effect. In our experiment, automatic selling devices do not allow for a better implementation of certain trading strategies due to better market access. Consequently, rational traders' disposition effects should not differ across treatments that include or exclude automatic selling devices. However, if investors have self-control problems, their disposition effect may be reduced by automatic selling devices. Investors with self-control problems may plan to realize losses but are reluctant to do so when losses actually occur. If such investors are aware of their selfcontrol problem (i.e., if they are sophisticated), they can commit to realizing

Ferris, Haugen, and Makhija (1988), Grinblatt and Keloharju (2001), Shapira and Venezia (2001), Locke and Mann (2005), Dhar and Zhu (2006), Kumar and Lim (2008), Kumar (2009), Kaustia (2010a), Seru, Shumway, and Stoffman (2010), Jin and Scherbina (2011), and Ben-David and Hirshleifer (2012).

2 The authors conducted this treatment to show that irrational beliefs in mean reversion do not cause the disposition effect in their trading environment. This conclusion follows from the observation that investors do not re-buy assets that were sold at a loss. 
losses through automatic selling devices and thereby reduce their disposition effects.

We implement three treatments in our laboratory experiment: a control treatment (from now on no limit treatment), a limit treatment, and a reminder treatment. In the no limit treatment, investors can (only) actively buy and sell assets. In the limit treatment, investors can additionally use automatic selling devices (stop-loss and take-gain orders). To do so, investors specify a lower and upper price limit when purchasing an asset (with the possibility of later adjustments). As soon as the price hits one of these limits, the automatic selling device sells all units of the respective asset. In the reminder treatment investors, as in the limit treatment, state price limits for which they plan to sell the assets and are informed if one of these limits is hit, but investors still have to decide on whether or not to realize the trade. As investors are randomly allocated to the different treatments, our design allows us to study whether automatic selling devices can causally reduce the disposition effect, as well as which elements of the automatic selling device (making plans vs. automatic selling) are crucial. In turn, we are able to identify whether committing to realize a loss before the loss occurs is of value to (sophisticated) investors.

By using the measure proposed by Odean (1998), who defines the DE as the difference between the proportion of winners realized (PWR) and the proportion of losers realized (PLR), we find that investors' disposition effects are significantly lower in the limit treatment than in the no limit and reminder treatment. Lower disposition effects in the limit treatment are the result of an increase in the PLRs, whereas PWRs do not significantly differ across treatments. These results are qualitatively robust to different definitions of reference prices, such as highest, lowest, first, last, and weighted purchase price. The reminder treatment allows us to identify which elements of the limit treatment causally reduce the disposition effect. As the disposition effects in reminder are as large as in the no limit treatment, the causal reduction of the disposition effect in the limit treatment stems from the fact that investors have the opportunity to commit to realizing losses ex ante, before these losses occur; this favors a preference-based explanation of the disposition effect that includes time-inconsistent behavior.

We complement a nascent literature studying explicit measures to reduce the disposition effect and highlight the role of time-inconsistent behavior of the disposition effect. Recently, Frydman and Rangel (2014) have shown that subjects' tendency to exhibit a disposition effect is less pronounced if information about a stock's purchase price is less salient. In line with models of realization utility (Barberis and Xiong 2012; Shefrin and Statman 1985; Ingersoll and Jin 2013), in which investors receive a utility burst when selling a risky asset and the size of the burst depends on the gain or loss relative to the purchase price, Frydman and Rangel (2014) find that making purchase price information less salient reduces the size of the disposition effect by $25 \%$. Similarly, our limit treatment may also reduce the salience of prices (as investors 
can decide on the sale before prices become known). However, a rational timeconsistent individual will anticipate the realization utility loss caused by the automated sale and therefore will be reluctant to commit to it. In addition, realization utility models assume that (realization) utility bursts only occur if the investor does not immediately repurchase the asset. In our trading environment investors who experience an automatic sale of a loss could avoid the negative utility burst by repurchasing the asset for the same price, but they do not do so. Thus, models of realization utility may explain our results only if they explicitly or implicitly model time-inconsistent behavior (see, e.g., Barberis 2012).

Alternative explanations for the disposition effect such as mental accounting (Thaler 1999, p. 189) also cannot explain our treatment effects without taking time-inconsistent behavior into account (explicitly or implicitly). It has also been put forward that active trading after a price change may refer to an immediate reaction to an event (i.e., to affectively hot decision-making; see Loewenstein 2005), whereas choosing limits that eventually cause an automatic sale may refer to decision making in a "cold" phase. This could lead to more deliberative choices when using automatic selling devices. ${ }^{3}$ However, if lower affect was the only reason for the reduction of the disposition effect, we should expect our reminder treatment to reduce the disposition effect (as investors can remind themselves about their deliberative choice). In a similar way, the reminder treatment may help investors to avoid cognitive dissonance. If investors are reluctant to sell losses because doing so means, acknowledging personal purchase failures (see, e.g., Chang, Solomon, and Westerfield 2016) being reminded about the ex ante plan to sell an asset at that loss should offset investors' cognitive dissonance. As the reminder treatment does not significantly reduce the disposition effect (but the automatic selling device does), we conclude that neither cognitive dissonance nor affect alone can explain our results.

Concerning the broader question of whether a preference-based or beliefbased explanation for the disposition effect is favorable, we provide at least two pieces of evidence in favor of a preference-based explanation. First, it is difficult to see how the ability to precommit to selling at a specific price in the future should affect beliefs. Second, explaining that the limit treatment increases the proportion of losses realized, but the proportion of gains realized remains unchanged is difficult to do with a belief-based explanation (unless there is an exogenous asymmetry in the belief updating process; see, for example, Kuhnen 2015 and the discussion in Ben-David and Hirshleifer 2012, 2517-8). However,

3 In recent work, Ploner (2014) studies differences in behavior of investors in a simple risk task with a focus on the hot-cold approach. Comparing conditional selling decisions in the strategy method (cold approach) with selling decisions after experiencing a loss (in the hot protocol), he finds that people are more likely to hold onto the risky asset in the hot approach (see also Imas 2016, for a comprehensive discussion of such realization effects). 
the observed asymmetry is in line with a preference-based explanation that includes time-inconsistent behavior. ${ }^{4}$

Apart from providing theoretical insights into the underlying reasons of the disposition effect we provide causal evidence on the effectiveness of automatic selling devices to reduce investors' disposition effects. Thereby, we complement several studies that use non-experimental data to investigate how stop-loss and take-gain orders relate to the disposition effect (see, e.g., Nolte 2012; Linnainmaa 2010; Richards et al. 2015).

\section{Experimental Design}

The general design of our experiment is similar to the stock market treatment in the experiment of Weber and Welfens (2007). Investors receive an initial endowment of 2000 experimental currency units to make portfolio decisions. Investors can trade six different assets labeled 1-6. The game consists of 34 rounds, starting in round -3 and ending in round 30 . In rounds -3 to -1 investors cannot trade but observe the price changes for the six assets. In all rounds 0-30 investors can buy and sell assets. For the rest of the paper we call rounds 0 to 30 "trading rounds." In trading rounds investors can purchase and sell assets from their portfolio according to the quantity of assets in their inventory and the number of points left on their account. The game ends in round 30. All assets remaining in the portfolio are sold automatically and the final earnings in experimental currency units are displayed.

A random process determines prices to ensure that investors' trading behavior is not affected by strategic market manipulation or any other interdependence between traders. In round -3 the price of each asset equals 100 experimental currency units and changes in each of the following rounds. In each period, the price either rises by $6 \%$ or drops by $5 \%$. The probability of the increase varies across the assets but is constant across the periods for each asset. The investors know this; that is, they know the size of the possible price increase or decrease, and they know that the price-change probabilities vary across asset but are constant across all rounds and independent of investors' trading activities. We implemented the following six probabilities of price increases for the six assets: $40 \%, 45 \%, 50 \%, 50 \%, 55 \%$, and $60 \%$. These probabilities were unknown to investors.

To find out whether the possibility to use stop-loss and take-gain orders can reduce the disposition effect we employ a between-subjects design, in which one group of randomly selected investors can use stop-loss and takegain orders whereas the control group has no such device. To allow for a within price development comparison, we form pairs of participants across treatments

4 We thank an anonymous referee for pointing this out. 
(one investor in the limit treatment and the other in the no limit treatment) who are confronted with the same randomly determined price paths. ${ }^{5}$

In the limit treatment, investors had to decide on a price limit below and a price limit above the current price. Whenever the price reached or exceeded these prices, the automatic selling device triggered a sale of all units of the respective asset. Investors had to choose limits when they bought a particular stock for the first time or when they increased the units of an asset in later rounds again from zero to a positive number. Non-binding limits of a price of 0 and 1,000 were possible and investors could adjust limits in every trading round. If investors only sold a fraction of their holdings of an asset or added some units of an asset to their existing holdings, there was the possibility but no need to set new price limits. The automatic selling device triggered a sale of all units of an asset as soon as one of the price limits was reached and sold the assets at the realized price. The automatic selling device informed investors if a price limit was hit. As investors could actively buy and sell assets in all trading rounds, it was possible to repurchase an automatically sold asset in the same round at the same round's price (with no bid-ask spread).

To isolate which elements of the automatic selling device causally reduce the disposition effect and thereby shed more light on the underlying theoretical reasons for the disposition effect, we conducted an additional treatment that we call reminder. In this treatment, investors faced the same decision making frame as investors in the limit treatment. Investors in the reminder treatment had to define a price below and a price above the current price, at which they plan to sell an asset. If investors wished not to state such a target, they could also enter a target price of 0 and 1,000. The choice and revision options of the price limits were the same as in the limit treatment. If a price limit was hit, the investor was informed (as in the limit treatment). In contrast to the limit treatment, no automatic selling device triggered a sale. Instead the investor herself had to decide whether or not to sell (or buy) assets actively in the given trading round.

During the experiment, each participant sat at a randomly assigned and separated PC terminal and received a copy of instructions. ${ }^{6}$ A set of control questions as well as a short on-screen trading example ensured the understanding of the game and the trading interface. If any participant repeatedly failed to answer control questions correctly, the experimenter provided an oral explanation. No form of communication was allowed during the experiment. We conducted the experimental sessions in February and April 2015, at the laboratory of the University of Konstanz. We collected the data

5 Whether the price of an asset increased or decreased was determined randomly by the computer (using the respective probability) at the point in time in which one of the two subjects advanced to the next trading round. For the treatment reminder, which is described below, we used the same random prices as in the limit and no limit treatments.

6 The Online Appendix provides a copy of the translated instructions. 
over three sessions, with 72 participants in total. We ran the treatments limit and no limit in parallel within a session, with random allocation of investors to the treatment condition. The treatment reminder was run in a single session using the random price developments from the earlier sessions. Participants received a show-up fee of 4 euros, which were added to the earnings from the trading experiment (where 200 points corresponded to 1 euro). The experiment took about one hour and 15 minutes, and average income (including the show-up fee) was about 17 euros. We programmed and conducted the experiment by using z-Tree (Fischbacher 2007). We recruited participants by using the online recruiting system ORSEE (Greiner 2004). Participants were part of the local subject pool, including undergraduate and graduate students of all fields of study.

\section{Measurement of the Disposition Effect}

To calculate the disposition effect, we build on the work of Odean (1998), whose method relates all sales to all possibilities to sell at a gain or a loss. An asset is regarded as a winner (loser), if the current price lies above (below) a certain reference price. For reasons of comparability (for instance, with Weber and Welfens 2007), we use the (quantity) weighted average purchase price as the reference price throughout the paper. ${ }^{7}$ The proportion of winners realized (PWR) and the proportion of losers realized (PLR) are defined as

$$
\begin{aligned}
& P W R=\frac{\text { units sold at a gain }}{\text { possible number of units to sell at again }}, \\
& P L R=\frac{\text { units sold at a loss }}{\text { possible number of units to sell at a loss }} .
\end{aligned}
$$

The disposition effect (DE) is defined as the difference between PWR and PLR $(\mathrm{DE}=\mathrm{PWR}-\mathrm{PLR})$. The DE measure ranges between -1 and 1 . ADE measure of zero means that the investor realizes winners and losers at the same rate relative to selling opportunities. For investors who generally refrain from selling assets that incur a loss but always realize gains, the DE equals one, because the PLR equals zero and the PWR equals one. For the other extreme, that is, if investors show the strongest eagerness to sell assets that incur a loss and never sell assets that yield a gain, the DE equals -1 , because the PLR equals one and the PWR equals zero.

\footnotetext{
7 We also conducted analyses using the first, last, lowest, and highest purchase price as reference prices. Qualitative results are robust if not reported otherwise.
} 
We measure sales and possibilities to sell at a gain or loss as follows. Sales at a gain (loss) correspond to the number of assets actually sold at a gain (loss), regardless of whether the asset was sold automatically or manually. Possibilities to sell at a gain (loss) correspond to the units of assets an investor can sell, for which current price is higher (lower) than the reference price. The possibilities to sell at a gain (loss) correspond to the units of assets an investor owns in each round for which the current price is higher (lower) than the reference price. ${ }^{8}$ We briefly illustrate this measure with an example. Let us assume an investor buys five units of an asset in round 1 and sells them in round 5. Let us further assume that the price decreased according to the reference price in round 2 but then increased according to the reference price in rounds 3,4 , and 5 such that in rounds 3,4 , and 5 the five units trade at a price above the reference price. We will count five possibilities to sell at a loss in round 2 and five possibilities to sell at a gain in each of rounds 3,4 , and 5, which gives a total of five possibilities to sell at a loss and 15 possibilities to sell at a gain.

Finally, note that we cannot measure the disposition effect if an investor never has the possibility to sell at a gain (loss), because the PWR (PLR) is not defined in this case. This exceptional case applies to one individual in the no limit and one in the limit treatment who both had no possibility to sell at a loss.

\section{Theoretical and Empirical Benchmarks}

Let us briefly discuss investors' optimal trading strategies and the resulting theoretical benchmarks for our experiment. Subjects know that the probabilities of price increases for each asset are constant over time but they do not know the actual probabilities. Assume a rational and risk-neutral subject who is willing to invest and has the same priors for the probabilities of a price increase for each asset. For such a subject investing in the asset with the highest price increase since the start is optimal. Because all assets start at the same price, the asset with the highest price increase is the asset with the highest current price. Thus, a rational and risk neutral subject with identical priors will either not invest or invest all her points in the asset(s) with the highest price. Hence, a simple rule of thumb, namely "invest all points in the asset with the highest price or do not invest" is optimal for risk neutral investors (given the information investors received in the experiment). This rule of thumb yields on average a negative DE measure. ${ }^{9}$ A second theoretical benchmark is random trading behavior, which would result in individual disposition effects

\footnotetext{
8 As investors can buy assets from round 0 on and all assets are automatically sold in round 30, the measure can be defined in periods 1 to 29 .

9 The DE measures that are the result of the simple trading heuristic are defined for 18 out of the 22 price developments (as the heuristic yields no possibility to sell at a loss for four price developments) and range from -1 to -0.625 .
} 


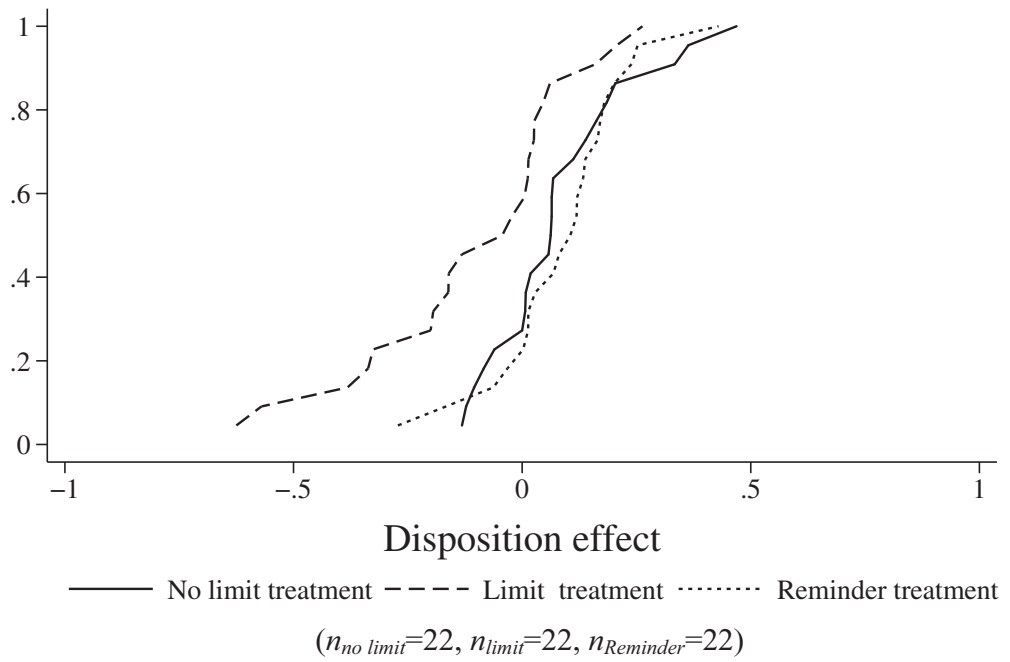

Figure 1

Cumulative distributions of individual DEs

being symmetrically distributed around zero. While these benchmarks help to interpret the obtained values of DEs in general, our main interest lies in comparing DEs across experimental treatments, which should not significantly differ if investors are trading rationally (or randomly). Consequently, we mainly focus on the empirical benchmark, that is, the distribution of DEs in the no limit treatment.

\section{Results}

We structure the results section in four parts. The first part focuses on the main research question: whether the possibility to use stop-loss and take-gain options causally reduces the disposition effect and if so, why. In Subsection 4.2 we discuss the portfolio choices of our investors in more detail. Subsection 4.3 presents limit use in the limit treatment, and in Subsection 4.4, we provide regression analyses on DEs and PLRs across treatments controlling for risk preferences, overconfidence and socio-economic background variables.

\subsection{Automatic selling devices and the disposition effect}

We first report whether the limit treatment causally reduces the disposition effect. Then we show whether the reduction is due to an increase in realized losses (i.e., through PLR) or due to a decrease in realized gains (i.e., through PWR). Finally, we report the results from the reminder treatment. To investigate whether the limit treatment is effective, we compare the distribution of DEs across the treatments (Figure 1), as well as how the DEs differ across treatments for given price developments (Figure 2). Figure 1 shows the cumulative 


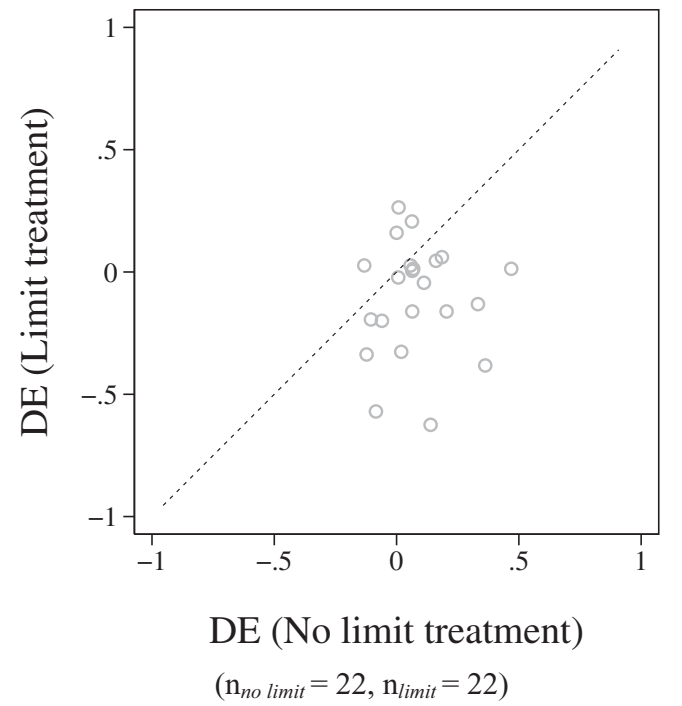

Figure 2

DE for investors facing same price development

distribution (cdf) of the individual disposition effects using the weighted average purchase price as the reference price. ${ }^{10}$ The cdf in the limit treatment is clearly to the left of the cdf for the no limit treatment; that is, DE values are significantly lower in the limit treatment (Kolmogorov-Smirnov test, $\mathrm{p}=0.002$ ). Further, referring to our random-trading benchmark, a binomial test rejects the $\mathrm{H}_{0}$ that investors are equally likely to have a positive or negative $\mathrm{DE}$ in the no limit $(\mathrm{p}=0.052)$ and reminder treatment $(\mathrm{p}=0.004)$, whereas it fails to reject this $\mathrm{H}_{0}$ in the limit treatment $(\mathrm{p}=0.832)$.

Figure 2 shows the DE for pairs of investors across treatments facing the same price development. Each point reflects how large the DE was for a specific price development in the no limit and limit treatment. It becomes clear from the figure that more observations are below or close to the $45^{\circ}$ line. That is, for most price developments, DEs are larger in the no limit treatment. A Wilcoxon signed-rank test rejects the equality of the population mean ranks $(p=0.008)$. We summarize these findings in Result 1.

Result 1: The disposition effect is significantly lower in the limit treatment than in the no limit treatment.

Separating the DE into its two components (PWR and PLR) makes it possible to disentangle whether the limit treatment reduces the disposition effect due

10 As the DEs for one individual in the no limit treatment and one individual in the limit treatment are not defined (as these investors had no possibility to sell any asset at a loss), we excluded these individuals, as well as the DEs/PLRs of those subjects, who experienced the same price developments from the figures and the nonparametric analyses. 
to a higher proportion of realized losses or due to a lower proportion of realized gains. ${ }^{11}$ Figure 3 shows the cumulative distributions for the PLR and PWR across treatments. The cdf of the PLR in the limit treatment first order stochastically dominates the cdf in the no limit treatment (KolmogorovSmirnov test, two-sided, $\mathrm{p}=0.049)$. However, we cannot reject the equality of distributions for the PWR (Kolmogorov-Smirnov test, two-sided, $\mathrm{p}=0.632$ ). We summarize our finding in Result 2:

Result 2: The limit treatment increases the proportion of losers realized but does not significantly affect the proportion of winners realized.

Results 1 and 2 show that the possibility to use automatic selling devices causally reduces the disposition effect by significantly increasing the proportion of losses realized. As the limit treatment does not provide better market access we can exclude that the reduction in DEs is due to the fact that rational traders are more able to implement optimal trading strategies. ${ }^{12}$ Instead, the limit treatment reduces the disposition effect either because it changes the way investors trade (as they think about price limits when purchasing assets) or because investors can use the automatic selling device as a commitment to sell assets at a loss before they experience the loss. The reminder treatment lets us disentangle these two possibilities. As in the limit treatment, in reminder investors also had to enter lower and upper price limits for which they planned to sell their assets and received a message if one of their price limits had been hit. ${ }^{13}$ However, in reminder no automatic selling device triggered a sale. Figures 1 and 3 show that the cumulative distribution functions of DEs and PLRs in reminder significantly differ from those in the limit treatment (Kolmogorov-Smirnov test, reminder vs. limit treatment, DE: $\mathrm{p}=0.007$, PLR: $\mathrm{p}=0.020$, PWR: $\mathrm{p}=0.872$ ) and overlap with those in the no limit treatment (Kolmogorov-Smirnov test, reminder treatment $v$ s. no limit treatment, DE: $p=0.394$, PLR: $p=0.109$, PWR: $\mathrm{p}=0.632$ ). Consequently, we conclude that it is not enough to make people think about price limits and remind them about these limits when they are hit to reduce the reluctance to realize losses. Instead, the limit treatment is effective, because it provides an opportunity to commit to selling at a loss before the loss actually occurs. We summarize this finding in Result 3:

11 Note that, consistent with previous findings by Weber and Welfens (2007), the correlation between the PLR and PWR in the no limit and limit treatment is small and insignificant (no limit treatment: Spearman's $\rho=-0.09$, p-value $=0.685$, limit treatment: $\rho=0.23$, p-value $=0.305$, reminder $: \rho=-0.01$, p-value $=0.965)$.

12 As this could be the case in the real world, we also conducted additional treatments in which market access was restricted. Results from these treatments are qualitatively similar and available on request. We thank an anonymous referee for pointing out the theoretical advantages of the environment with unrestricted access.

13 Note that limit choices (measured as the individual average difference between trading prices and the limit, excluding those who did not set a limit) do not significantly differ between the reminder and limit treatment (Kolmogorov-Smirnov test, reminder treatment vs. limit treatment, lower limits: $\mathrm{p}=0.157$, upper limits: $\mathrm{p}=0.434$ ). Also, the number of subjects who never set a lower limit (upper limit) does not significantly differ (Fisher-exact test, for lower limits: $\mathrm{p}=0.281$, for upper limits: $\mathrm{p}=0.185$ ). 


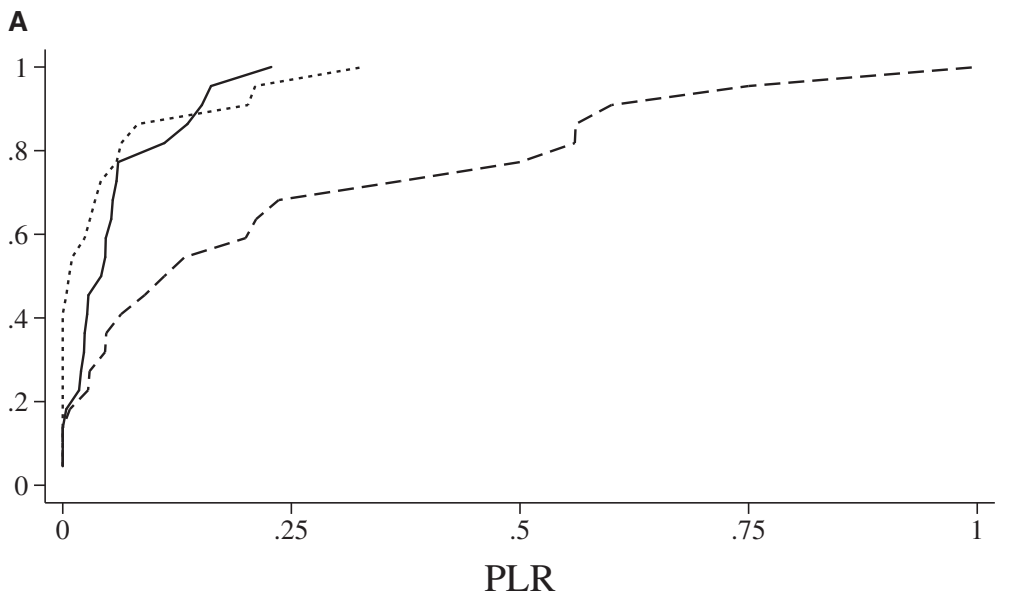

— No limit treatment ---- Limit treatment ......... Reminder treatment

$\left(n_{\text {no limit }}=22, n_{\text {limit }}=22, n_{\text {Reminder }}=22\right)$

B

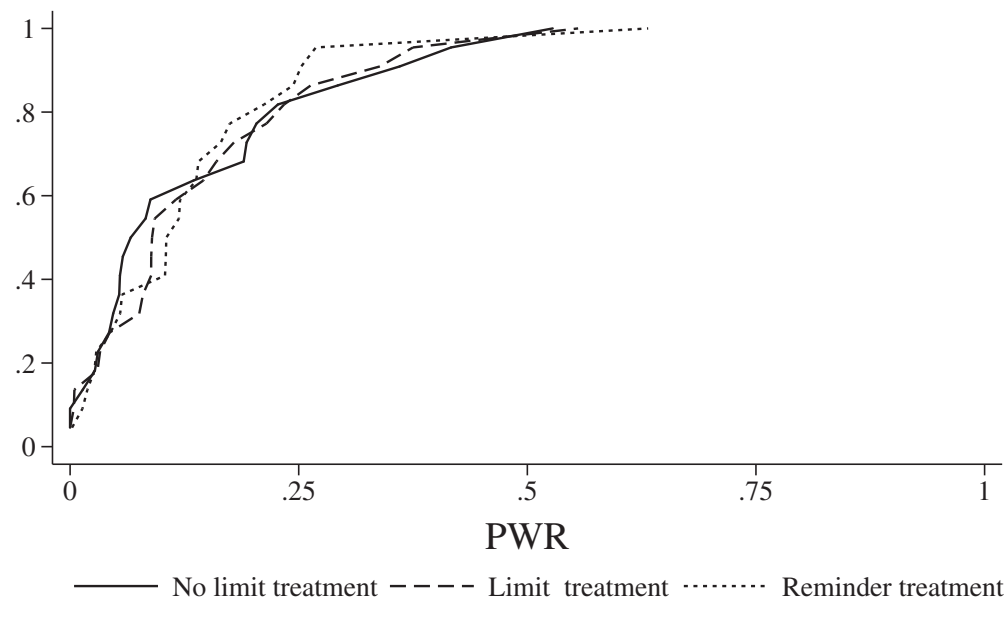

$\left(n_{\text {No limit }}=22, n_{\text {Limit }}=22, n_{\text {Reminder }}=22\right)$

Figure 3

PLR and PWR across treatments. PLR is presented in (A), and PWR is presented in (B).

Result 3: Reminders about selling plans are ineffective.

\subsection{Investors' portfolio choices}

In this section we briefly shed light on investors' portfolio choices. At the beginning of the experiment, investors hold, on average, about $50 \%$ of their 


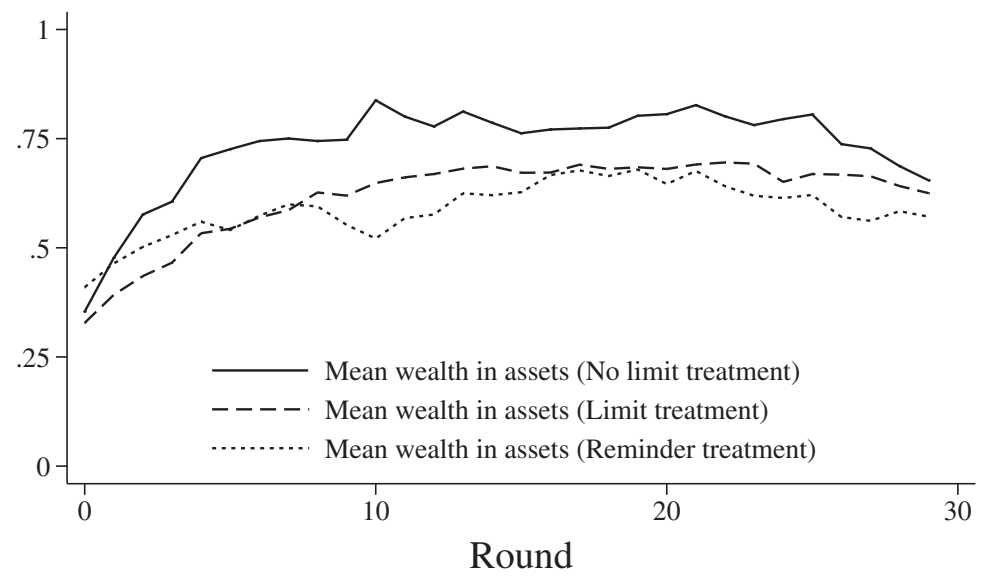

Figure 4

Share of wealth in risky assets across treatments

wealth in risky assets (see Figure 4). This share is stable over time in the limit treatment and reminder. However, investors in the no limit treatment increase the share of wealth invested in assets over time to up to $75 \%$ (as they reduce the absolute number of points on their account over time). To understand this development better, we further present investors' relative portfolio choice according to price realizations. We rank the assets according to their relative price level from rank 1 (highest price) to rank 6 (lowest price) for each round. If two or more assets have the same price, both receive the upper rank and the respective rank(s) below are empty (e.g., if two assets have the highest price both receive rank 1 , and rank 2 is consequently empty). ${ }^{14}$ In a next step we calculate the relative quantities of each asset for each round. ${ }^{15}$ Figure 5 shows the average relative quantity by treatment across rounds.

The relative quantity of the asset with the highest price in the limit treatment is, on average, (round 0 to 29 ) $38.2 \%$, whereas it is only $25.9 \%$ in the no-limit treatment (Wilcoxon signed-rank test, $\mathrm{p}=0.133$ ). The average relative quantity of the asset with the lowest price is $12.8 \%$ in the limit treatment and $19.9 \%$ in the no-limit treatment (Wilcoxon signed-rank test, $\mathrm{p}=0.184$ ). In reminder average relative quantity of the asset with the highest price amounts to $24.4 \%$ (Wilcoxon signed-rank test, reminder vs. limit treatment $\mathrm{p}=0.09$, reminder vs. no limit treatment $\mathrm{p}=0.787$ ) and the average relative quantity of the asset

14 Note that this may lead to an overrepresentation of some ranks in some rounds, but does not systematically affect the treatment comparison because for each price development we have one investor in each treatment.

15 Relative quantity $=\frac{\# \text { of units held in risky good with price rank } i}{\sum_{j=1}^{6} \# \text { of units held in risky good with price rank } j}$. 


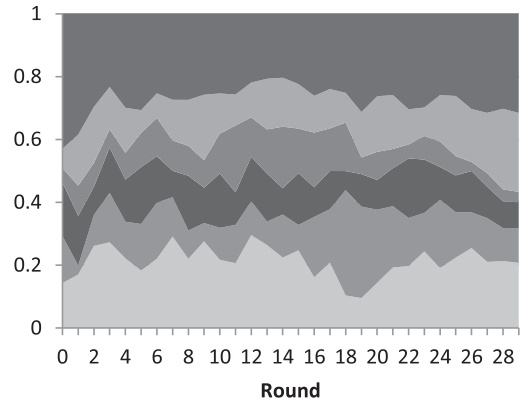

No limit treatment

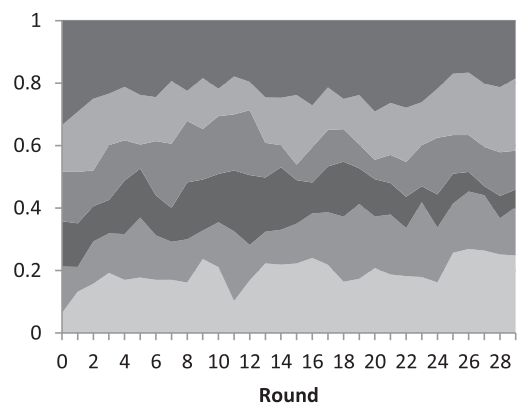

Reminder treatment

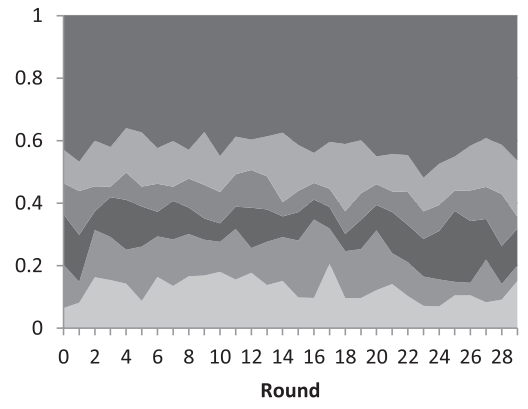

Limit treatment

Rank 1 (highest Price)

Rank 2

Rank 3

- Rank 4

- Rank 5

Rank 6 (lowest price)

Figure 5

Average relative quantities in the treatments

with the lowest price to $19.4 \%$ (Wilcoxon signed-rank test, reminder vs. limit treatment $\mathrm{p}=0.379$ reminder $\mathrm{vs}$. no limit treatment $\mathrm{p}=0.865)$.

Interestingly, we do not observe a general time trend with respect to portfolio choice. Instead, after few rounds investors in the limit treatment tend to hold the asset with the highest price more frequently than in the no limit and reminder treatment. Consequently, for the same price developments, traders in the limit treatment have significantly fewer possibilities to sell at a loss $\left(\mathrm{PSL}_{\text {nolimit }}=\right.$ 165.05 vs. PSL $_{\text {limit }}=74.09, \mathrm{p}<0.01$ ) and tend to have (insignificantly) more possibilities to sell at a gain $\left(\mathrm{PSG}_{\text {nolimit }}=218.09\right.$ vs. $\mathrm{PSG}_{\text {limit }}=224.09$, $\mathrm{p}=0.906)$.

\subsection{Limit use}

Table 1 provides an overview on DEs across treatments and the use of limits. First note that not all investors in the limit treatment make use of the limit option. Thirteen out of 22 investors (for whom the DE is defined) use both limits. Two investors use only the lower limit and no investor uses only the upper limit. The investors who use both limits use the upper limit in about $44 \%$ of the cases and the lower limit in about $50 \%$ of the cases (Wilcoxon 
Table 1

DE, PLR, PWR, and limit use

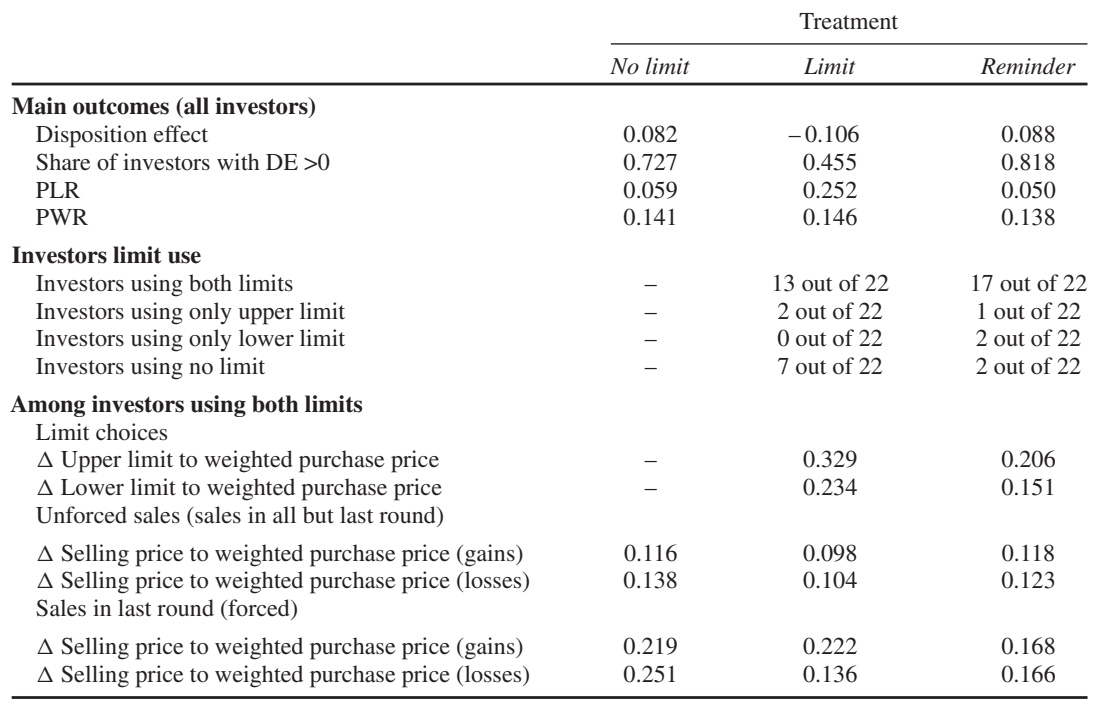

Note: Table reports means for the 22 price developments, for which the DEs are defined in all treatments.

signed-rank test, $\mathrm{p}=0.47$ ). Disposition effects of the investors who make use of both limits are significantly smaller than disposition effects of investors in the no limit treatment $\left(\mathrm{DE}_{\text {limit treatment_usedlimit }}=-0.124\right.$ vs. $\mathrm{DE}_{\text {no limit treatment }}=$ 0.082, Kolmogorov-Smirnov-Test, $\mathrm{p}=0.036$ ). Differences between the DEs of the seven investors who do not use any limits and the DEs in the no limit treatment are statistically insignificant $\left(\mathrm{DE}_{\text {limit treatment_usednolimit }}=-0.078 \mathrm{vs}\right.$. $\mathrm{DE}_{\text {no limit treatment }}=0.082$, Kolmogorov-Smirnov-Test, $\mathrm{p}=0.218$ ); reflecting that these investors may either be individuals with perfect self-control or naïve investors who underestimate their reluctance to actively sell assets trading at a loss. In reminder, slightly more investors use both limits $\left(\chi^{2}\right.$ test, $\left.\mathrm{p}=0.195\right)$ but reminders are ineffective, also for investors using them $\left(\mathrm{DE}_{\text {reminder_usedlimit }}=\right.$ 0.099 vs. $\mathrm{DE}_{\mathrm{no}}$ limit treatment $=0.082$, Kolmogorov-Smirnov-Test, $\mathrm{p}=0.163$ ).

To investigate whether investors use lower and upper limits in different ways we calculate the average relative distance of limits to the current trading price (for all trading rounds). We find that, in the limit treatment, the average relative distance to the upper limit (0.329) tends to be larger than the average relative distance to the lower limit, but differences are statistically insignificant $(0.234$, Wilcoxon signed-rank test, $\mathrm{p}=0.167)$. In the reminder treatment, the upper distance amounts to 0.206 and is significantly larger than the distance to the lower limit $(0.151$, Wilcoxon signed-rank test, $\mathrm{p}=0.057)$.

Finally, we report the size of realized gains or losses, that is, the relative distances of the weighted purchase price to the selling price across treatments. For all unforced realizations, that is, for all gains and losses realized before the 
last round, losses and gains of investors using both limits tend to be smaller in the limit than in the no limit treatment but the differences are statistically insignificant (Wilcoxon rank-sum test, two-sided, using individual averages, for losses $\mathrm{p}=0.627$, for gains $\mathrm{p}=0.556$ ). Relative distances for forced sales in the last round amount to 0.251 for losses and 0.219 for gains in the no limit treatment and to 0.136 for losses and 0.222 for gains in the limit treatment (Wilcoxon rank-sum test, two-sided, for losses $\mathrm{p}=0.521$ and for gains $\mathrm{p}=0.962$ ). While realized losses in the last round tend to be smaller than gains ( 0.136 vs. 0.222$)$ in the limit treatment, gains and losses investors realize in the last round are of similar size in the no limit treatment (as well as in the reminder treatment).

Our main result (Result 1) thus reflects three behavioral aspects. First, and most importantly, investors who are offered the possibility to sell gains and losses automatically are less reluctant to sell losses in general (see Section 4.1). Second, investors in the limit treatment are also more likely to hold assets with higher prices (see Section 4.2). Third, investors in the limit treatment tend to set the lower limits closer to current prices than upper limits and tend to use the upper limit slightly less frequently than the lower limit (see Section 4.3). In turn, investors in the limit treatment realize more losses than gains than in the no limit and reminder treatments.

\subsection{Individual characteristics and final payoffs}

Finally, we provide a robustness test on our treatment effects by reporting results from OLS regressions including controls for individual characteristics (see Table 2). We elicited the additional control variables in a post-experimental questionnaire. Our specifications control for the following self-stated variables: Investors' average math grade in final secondary school examinations (standardized with higher values corresponding to better grades), investors' gender (using a male dummy), investors' risk-taking behavior in monetary decisions (ranging from not at all risk seeking to very risk seeking, see Dohmen et al. 2011), a dummy for investors' stock market experience, and a standardized measure of investors' overconfidence. ${ }^{16}$ Models (1a) and (1b) confirm the nonparametric tests: the limit treatment reduces the disposition effect significantly, even if we control for individual background variables (which play a minor role compared to the treatment effect). In model (1c), we include how frequently individuals use the upper and lower limit, on average, as additional explanatory variables. Model (1c) shows again that the limit treatment, that is, having the possibility to use the automatic selling device, reduces the DE significantly. Within the limit treatment, investors who use the

16 The overconfidence measure is calculated as follows: Participants had to answer six knowledge questions requiring a numerical answer (see the Online Appendix). They had to do so by giving confidence intervals. For each question, subjects were ranked by how far the true answer fell outside of their confidence interval. The sum of ranks for each question determined the overall rank. In the regression analysis, we use the standardized sum of ranks. 
Table 2

OLS regression on DEs, PLRs, and total points earned

\begin{tabular}{|c|c|c|c|c|c|c|c|}
\hline Dep. var. & $\begin{array}{l}(1 \mathrm{a}) \\
\mathbf{D E}\end{array}$ & $\begin{array}{l}\text { (1b) } \\
\text { DE }\end{array}$ & $\begin{array}{l}\text { (1c) } \\
\text { DE }\end{array}$ & $\begin{array}{l}(2 a) \\
\text { PLR }\end{array}$ & $\begin{array}{l}(2 \mathrm{~b}) \\
\text { PLR }\end{array}$ & $\begin{array}{l}(2 \mathrm{c}) \\
\text { PLR }\end{array}$ & $\begin{array}{c}\text { (3) } \\
\text { Total points }\end{array}$ \\
\hline \multicolumn{8}{|l|}{ Treatment effect } \\
\hline Limit treatment & $\begin{array}{l}-\mathbf{- 0 . 2 2 1} * * * \\
(0.0682)\end{array}$ & $\begin{array}{c}-\mathbf{0 . 2 2 6} * * * * \\
(0.0771)\end{array}$ & $\begin{array}{r}\mathbf{- 0 . 2 2 4} * \\
(0.109)\end{array}$ & $\begin{array}{l}\mathbf{0 . 1 8 5} * * * \\
(0.0596)\end{array}$ & $\begin{array}{l}\mathbf{0 . 1 9 7 * * *} \\
(0.0584)\end{array}$ & $\begin{array}{c}\mathbf{0 . 1 3 1} * \\
(0.0632)\end{array}$ & \\
\hline Reminder & $\begin{array}{c}-0.0397 \\
(0.0635)\end{array}$ & $\begin{array}{c}-0.0401 \\
(0.0696)\end{array}$ & $\begin{array}{c}-0.0403 \\
(0.115)\end{array}$ & $\begin{array}{c}-0.00176 \\
(0.0225)\end{array}$ & $\begin{array}{c}0.00593 \\
(0.0321)\end{array}$ & $\begin{array}{r}-0.0996 \\
(0.0932)\end{array}$ & \\
\hline \multicolumn{8}{|l|}{ Limit use } \\
\hline $\begin{array}{l}\text { Use of upper limit } \\
\text { (share) }\end{array}$ & & & $\begin{array}{c}0.0553 \\
(0.0648)\end{array}$ & & & $\begin{array}{c}0.00503 \\
(0.0800)\end{array}$ & \\
\hline $\begin{array}{l}\text { Use of lower limit } \\
\text { (share) }\end{array}$ & & & $\begin{array}{r}-0.0519 \\
(0.0963)\end{array}$ & & & $\begin{array}{l}0.116 \\
(0.0843)\end{array}$ & \\
\hline $\begin{array}{l}\text { Disposition effect } \\
\text { (standardized) }\end{array}$ & & & & & & & $\begin{array}{c}-\mathbf{2 1 0 . 7 7 8} * * * \\
(63.038)\end{array}$ \\
\hline \multicolumn{8}{|l|}{ Controls } \\
\hline $\begin{array}{l}\text { Math grade } \\
\text { (standardized) }\end{array}$ & & $\begin{array}{c}0.0130 \\
(0.0274)\end{array}$ & $\begin{array}{c}0.0150 \\
(0.0287)\end{array}$ & & $\begin{array}{c}-0.0255 \\
(0.0204)\end{array}$ & $\begin{array}{c}-0.0291 \\
(0.0221)\end{array}$ & $\begin{array}{c}66.057 \\
(51.647)\end{array}$ \\
\hline Male & & $\begin{array}{c}0.0428 \\
(0.0434)\end{array}$ & $\begin{array}{c}0.0448 \\
(0.0422)\end{array}$ & & $\begin{array}{c}-0.0332 \\
(0.0385)\end{array}$ & $\begin{array}{c}-0.00793 \\
(0.0473)\end{array}$ & $\begin{array}{l}\text { 338.351**** } \\
(112.722)\end{array}$ \\
\hline $\begin{array}{l}\text { Risk taking (money) } \\
\text { (standardized) }\end{array}$ & & $\begin{array}{c}0.0370 \\
(0.0223)\end{array}$ & $\begin{array}{c}0.0337 \\
(0.0248)\end{array}$ & & $\begin{array}{l}-\mathbf{0 . 0 3 7 1} * \\
(0.0193)\end{array}$ & $\begin{array}{r}-0.0290 \\
(0.0192)\end{array}$ & $\begin{array}{c}58.489 \\
(72.369)\end{array}$ \\
\hline $\begin{array}{l}\text { Overconfidence } \\
\text { (standardized) }\end{array}$ & & $\begin{array}{c}-0.00769 \\
(0.0343)\end{array}$ & $\begin{array}{c}-0.0091 \\
(0.0364)\end{array}$ & & $\begin{array}{c}0.0131 \\
(0.0215)\end{array}$ & $\begin{array}{c}0.00975 \\
(0.0215)\end{array}$ & $\begin{array}{c}-\mathbf{1 5 1 . 4 0 8} * * * \\
(51.364)\end{array}$ \\
\hline $\begin{array}{l}\text { Stock market } \\
\text { experience (std.) }\end{array}$ & & $\begin{array}{c}-0.0459 \\
(0.0777)\end{array}$ & $\begin{array}{c}-0.0428 \\
(0.0804)\end{array}$ & & $\begin{array}{l}\mathbf{0 . 1 3 5} * * * \\
(0.0418)\end{array}$ & $\begin{array}{l}\mathbf{0 . 1 2 4} * * * \\
(0.0407)\end{array}$ & $\begin{array}{c}-133.286 \\
(164.715)\end{array}$ \\
\hline Constant & $\begin{array}{r}\mathbf{0 . 1 1 9} * * \\
(0.0497)\end{array}$ & $\begin{array}{l}\mathbf{0 . 1 0 5}^{*} \\
(0.0565)\end{array}$ & $\begin{array}{l}\mathbf{0 . 1 0 3}^{*} \\
(0.0557)\end{array}$ & $\begin{array}{l}\mathbf{0 . 0 5 6 4} * * * \\
(0.0129)\end{array}$ & $\begin{array}{c}0.0451 \\
(0.0323)\end{array}$ & $\begin{array}{c}0.0335 \\
(0.0331)\end{array}$ & $\begin{array}{l}\mathbf{2 3 9 0 . 1 0 0 * * *} \\
(69.775)\end{array}$ \\
\hline Num. participants & 70 & 70 & 70 & 70 & 70 & 70 & 70 \\
\hline Independent obs. & 24 & 24 & 24 & 24 & 24 & 24 & 24 \\
\hline R-squared & 0.184 & 0.234 & 0.238 & 0.206 & 0.320 & 0.353 & 0.354 \\
\hline
\end{tabular}

Columns 1a-1c present DEs; Columns 2a-2c present PLRs; and Column 3 presents total points earned. Robust standard errors are in parentheses and clustered on 24 different price developments. *** $\mathrm{p}<0.01$, ** $\mathrm{p}<0.05$, * $\mathrm{p}<0.1$ The variables use of lower limit and use of upper limit equal zero in the no limit treatment. Note: The regressions exclude the two participants for whom the PLR and DE are undefined.

lower limit more frequently tend to also have lower DEs. ${ }^{17}$ Investors using the upper limit more frequently tend to have higher DEs. However, the coefficients for limit use are small and statistically insignificant.

Models (2a-2c) repeat the analysis for investors' PLRs. In line with the nonparametric results, the limit treatment significantly increases investors' PLRs. Finally, model (3) relates the standardized disposition effects to the total number of points earned in the experiment. On average, an increase by one standard deviation of the individual DE decreases the total number of points earned by around 211 points. $^{18}$

17 Note that limit use in these regressions is defined as " 0 " for the no limit treatment and corresponds to the average limit use of an investor in the limit and reminder treatment.

18 It is worthwhile to note that although the limit treatment significantly reduces the disposition effect, it does not significantly increase the total number of points earned in our experiment. The median number of tota points is 2,561.9, whereas the median for the investors in the limit treatment is 2,584.45 (Wilcoxon signedrank test, $\mathrm{p}>0.10$ ). However, in our trading environment, it is, by design, likely that a significant difference in disposition effects translates into significant differences in total points earned with a longer trading horizon. 


\section{Discussion and Conclusion}

We investigated the role of stop-loss and take-gain orders for the disposition effect in a trading environment that abstracts from several explanations for the disposition effect (such as explicit transaction costs, tax reasons, portfolio balancing and beliefs in mean reversion). In the experimental treatments, investors can either (1) only actively sell assets (no limit treatment), (2) have the additional possibility to sell assets by using automatic stop-loss and take-gain options (limit treatment), or (3) can prespecify selling plans and are reminded about the selling plans if a price limit is hit (reminder treatment). Our results provide evidence that automatic selling devices causally reduce the disposition effect by helping investors to realize their losses whereas reminders about selling plans are ineffective.

The findings from our experiment highlight the role of time-inconsistent behavior for the disposition effect. The limit treatment allows our investors to commit to selling an asset that trades at a loss before the loss actually occurs, and results in relatively low disposition effect measures. Neither the reminder treatment nor the no limit treatment offer this opportunity and both yield significantly higher disposition effects. Rational behavior as well as alternative utility models that do not (explicitly or implicitly) include timeinconsistencies cannot explain these treatment effects (i.e., the reduction of investors' disposition effect through automatic selling devices). Explanations for the disposition effect, such as prospect theory, pride seeking, and regret minimization, or theories of realization utility need to model time-inconsistent behavior explicitly or implicitly (see Barberis 2012) to be able to explain why automatic sales may help to reduce the disposition effect. Further, as disposition effects in the reminder treatment are not lower than in the no limit treatment, it is unlikely that lower affect in decision making (hot vs. cold effects; see also Loewenstein 2005) or theories of cognitive dissonance, such as investors' avoidance of acknowledging personal purchase failures (see, e.g., Chang, Solomon, and Westerfield 2016) alone can explain the reduction of investors' disposition effects.

In our experiment, automatic selling devices helped investors to increase the proportion of losers realized but did not affect the proportion of winners realized. This asymmetric impact of the limit treatment on the disposition effect suggests that time-inconsistent behavior matters indeed for the disposition effect. In contrast to stop-loss orders, take-gain orders do not allow investors to commit postponing (impulsive) trades at a gain. Instead, if at all, take-gain orders may remind investors about the size of gains they planned to realize ex ante. Future research may thus investigate whether investors who have an impulsive inclination to realize small short term gains may benefit from a trading device that allows them to ex ante commit to realizing gains later (at a larger prespecified size). 


\section{References}

Barberis, N. 2012. A model of casino gambling. Management Science 58:35-51

Barberis, N., and W. Xiong. 2009. What drives the disposition effect? An analysis of a long-standing preferencebased explanation. Journal of Finance 64:751-84.

\section{Realization utility. Journal of Financial Economics 104:251-71.}

Ben-David, I., and D. Hirshleifer. 2012. Are investors really reluctant to realize their losses? Trading responses to past returns and the disposition effect. Review of Financial Studies 25:2485-532.

Bleichrodt, H., A. Cillo, and E. Diecidue. 2010. A quantitative measurement of regret theory. Management Science 56:161-75.

Chang, T. Y., D. H. Solomon, and M. M. Westerfield. 2016. Looking for someone to blame: Delegation, cognitive dissonance, and the disposition effect. Journal of Finance 71:267-302.

Dhar, R., and N. Zhu. 2006. Up close and personal: Investor sophistication and the disposition effect. Management Science 52:726-40.

Dohmen, T., A. Falk, D. Huffman, U. Sunde, J. Schupp, and G. G. Wagner. 2011. Individual risk attitudes: Measurement, determinants, and behavioral consequences. Journal of the European Economic Association 9:522-50.

Ferris, S. P., R. A. Haugen, and A. K. Makhija. 1988. Predicting contemporary volume with historic volume at differential price levels: Evidence supporting the disposition effect. Journal of Finance 43:677-97.

Fischbacher, U. 2007. z-Tree: Zurich toolbox for ready-made economic experiments. Experimental Economics 10:171-78.

Frydman, C., N. Barberis, C. Camerer, P. Bossaerts, and A. Rangel. 2014. Using neural data to test a theory of investor behavior: An application to realization utility. Journal of Finance 69:907-946.

Frydman, C. and A. Rangel. 2014. Debiasing the disposition effect by reducing the saliency of information about a stock's purchase price. Journal of Economic Behavior \& Organization 107:541-52.

Greiner, B. 2004. An online recruitment system for economic experiments. In Forschung und wissenschaftliches Rechnen GWDG Bericht 63, ed. K. Kremer and V. Macho, 79-93. Göttingen: Gesellschaft für Wissenschaftliche Datenverarbeitung.

Grinblatt, M., and M. Keloharju. 2001. What makes investors trade? Journal of Finance 56:589-616.

Henderson, V. 2012. Prospect theory, liquidation, and the disposition effect. Management Science 58:445-60.

Hens, T., and M. Vlcek. 2011. Does prospect theory explain the disposition effect? Journal of Behavioral Finance $12: 141-57$.

Imas, A. 2016. The realization effect: Risk-taking after realized versus paper losses. American Economic Review 106:2086-109.

Ingersoll, J. E., and L. J. Jin. 2013. Realization utility with reference-dependent preferences. Review of Financial Studies 26:723-67.

Jin, L., and A. Scherbina. 2011. Inheriting losers. Review of Financial Studies 24:786-820.

Kaustia, M. 2010a. Disposition effect. In Behavioral finance (Robert W. Kolb Series in Finance), eds. H. K. Baker and J. R. Nofsinger. Hoboken, NJ: John Wiley and Sons.

Prospect theory and the disposition effect. Journal of Financial and Quantitative Analysis 45:791-812

Kuhnen, C. M. 2015. Asymmetric learning from financial information. Journal of Finance 70:2029-62.

Kumar, A. 2009. Hard-to-value stocks, behavioral biases, and informed trading. Journal of Financial and Quantitative Analysis 44:1375-401. 
Kumar, A., and S. S. Lim. 2008. How do decision frames influence the stock investment choices of individual investors? Management Science 54:1052-64.

Li, Y., and L. Yang. 2013. Prospect theory, the disposition effect, and asset prices. Journal of Financial Economics 107:715-39.

Linnainmaa, J. T. 2010. Do limit orders alter inferences about investor performance and behavior? Journal of Finance 65:1473-506.

Locke, P. R., and S. C. Mann. 2005. Professional trader discipline and trade disposition. Journal of Financial Economics 76:401-44.

Loewenstein, G. 2005. Hot-cold empathy gaps and medical decision making. Health Psychology 24:S49-S56.

Muermann, A., and J. M. Volkman. 2006. Regret, pride, and the disposition effect. Available at SSRN 930675.

Nolte, I. 2012. A detailed investigation of the disposition effect and individual trading behavior: a panel survival approach. European Journal of Finance 18:1-35.

O'Curry Fogel, S., and T. Berry. 2006. The disposition effect and individual investor decisions: The roles of regret and counterfactual alternatives. Journal of Behavioral Finance 7:107-16.

Odean, T. 1998. Are investors reluctant to realize their losses? Journal of Finance 53:1775-98.

Ploner, M. 2014. Hold on to it? An experimental analysis of the disposition effect. Cognitive and $\mathrm{PhD}$, University of Trento, Italia.

Richards, D. W., J. Rutterford, D. Kodwani, and M. Fenton-O'Creevy. 2015. Stock market investors' use of stop losses and the disposition effect. European Journal of Finance 2:130-52.

Seru, A., T. Shumway, and N. Stoffman. 2010. Learning by trading. Review of Financial Studies 23:705-39.

Shapira, Z., and I. Venezia. 2001. Patterns of behavior of professionally managed and independent investors. Journal of Banking \& Finance 25:1573-87.

Shefrin, H., and M. Statman. 1985. The disposition to sell winners too early and ride losers too long: Theory and evidence. Journal of Finance 40:777-90.

Thaler, R. 1999. Mental accounting matters. Journal of Behavioral Decision Making 12:183-206.

Weber, M., and C. F. Camerer. 1998. The disposition effect in securities trading: An experimental analysis. Journal of Economic Behavior \& Organization 33:167-84.

Weber, M., and F. Welfens. 2007. An individual level analysis of the disposition effect: Empirical and experimental evidence. Sonderforschungsbereich 504, No. 07-44. 